\begin{tabular}{|c|c|}
\hline$\$$ sciendo & 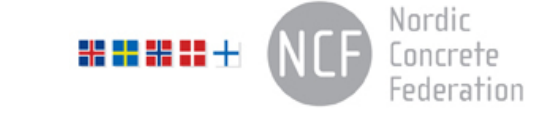 \\
\hline $\begin{array}{l}\text { (C) Article authors. This is an open access article distributed under } \\
\text { the Creative Commons Attribution-NonCommercial-NoDerivs } \\
\text { licens. (http://creaticecommons.org/licenses/by.nc-nd/3.0/). }\end{array}$ & $\begin{array}{l}\text { ISSN online } 2545-2819 \\
\text { ISSN print } \quad 0800-6377\end{array}$ \\
\hline DOI: $10.2478 /$ ncr-2021-0007 & $\begin{array}{r}\text { Received: March 30, } 2021 \\
\text { Revision received: Sept. 16, } 2021 \\
\text { Accepted: Sept. 16, } 2021\end{array}$ \\
\hline
\end{tabular}

\title{
Static and Dynamic Four-Point Flexural Tests of Concrete Beams with Variation in Concrete Quality, Reinforcement Properties and Impact Velocity
}

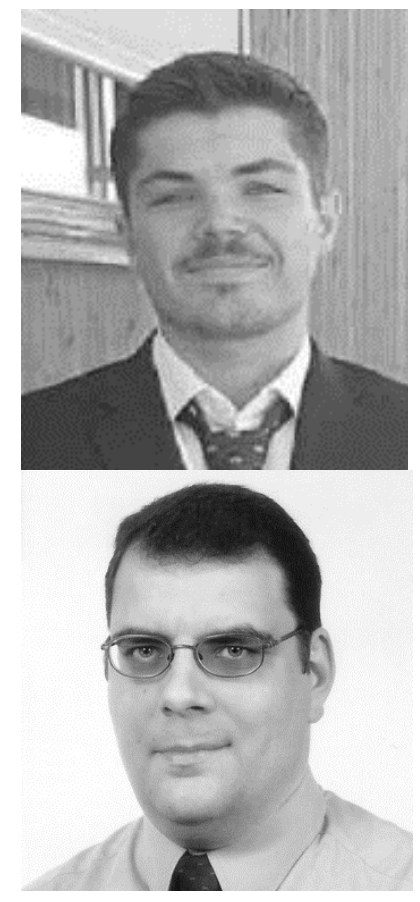

\author{
Viktor Peterson \\ M.Sc., Ph.D. Student \\ KTH Royal Institute of Technology \\ Division of Concrete Structures \\ SE-100 44 STOCKHOLM, Sweden \\ e-mail: viktor.peterson@byv.kth.se
}

\begin{abstract}
Anders Ansell
Ph.D., Professor

KTH Royal Institute of Technology

Division of Concrete Structures

SE-100 44 STOCKHOLM, Sweden

e-mail: anders.ansell@byv.kth.se
\end{abstract}

\begin{abstract}
This paper discusses the results from three experimental test series previously conducted. The tests consist of quasi-static monotonic and dynamic four-point flexural tests on reinforced concrete beams. The effect of varying material and load parameters on the plastic strain distribution and energy absorbed by the reinforcement is discussed. The main findings are the significant effect of the post-elastic region of the steel reinforcement and the impact velocity during dynamic loading. The results will be used to validate and construct numerical models in future work, where the findings presented can be investigated further.
\end{abstract}

Key words: Protective concrete structures, ductility, energy absorption capacity, reinforcement quality, impulsive loads, impact velocity, mild and stiff steels. 
1.

\section{BACKGROUND}

Protective concrete structures are designed with the purpose to protect people and equipment within the structure from damage caused by impulsive loads, e.g. collisions or explosions. Impulsive loads cause momentaneous large-amplitude pressure, and consequently a dynamic response of the structure [1]. The mechanical energy of the dynamic response must be absorbed by the structure for the motion to come to a halt [2]. Deformation work applied to reinforced concrete structures is absorbed through fracture mechanic processes in the concrete and plastic deformation [3]. The plastic deformation is a product of inelastic compression of the concrete and yielding of the reinforcement [4], and the elements are in general designed such that the reinforcement yield to a large extent before failing to sustain a ductile deformation mode [5]. This indicates that the tensile properties of the reinforcement play a governing role in the energy absorption capacity of reinforced concrete elements designed for ductility. The guidelines for the design of Swedish protective concrete structures were established at the end of the 1970s and consider data for steel reinforcement used at that time, see e.g. [6]. Modern steel reinforcement shows a larger yield strength when compared to the old reinforcement qualities which indicate a degree of cold working taking place during the modern manufacturing processes. This results in a lower ratio of the ultimate strength to the yield strength; while this ductility ratio used to be close to 1.5 , it sometimes goes as low as 1.05 today $[7,8,9]$. The reduction of the ductility ratio is predicted to decrease the rotation capacity and consequently the energy absorption capacity of reinforced concrete elements used in protective structures. To investigate this phenomenon an experimental test program sponsored by the Swedish defence was conducted. The experiments were performed during 2000-2005 [10], and consisted of static [7,9,11], as well as dynamic [8,9] tests on simply supported reinforced concrete beams, and similar tests were also conducted on continuous multi-support beams $[12,13,14]$. An overview of the results found for the simplysupported beams has previously been presented [15].

This paper aims to summarize relevant experimental results where load and material parameters were varied, and through discussions of the results perform sensitivity analyses. The goal of each analysis, conducted in Sections 4.1-4.5, is to compare the results for beams where only one parameter is varying, such that its effect can be deduced. The findings of the sensitivity study primarily aid the understanding of the plastic strain distribution response of reinforced concrete structures subjected to static and impulsive loading. This response is important to understand as it governs the energy absorption capacity of the structural element, which will be showcased in the paper. The sensitivity analysis will, furthermore, aid forthcoming numerical modelling of similar structures under impulsive loading conditions as this paper is part of a larger project, focusing on explosions in a densified urban environment. This large-scale project is a collaboration between the Concrete Division at KTH Royal Institute of Technology and the Structural Engineering Division at Chalmers University of Technology.

\section{2.}

\section{MATERIAL TESTING}

Results from three test series, previously presented in technical reports $[7,8,9]$, are summarized, evaluated and commented on in this paper. Each of the three reports covered material tests on both the concrete and the reinforcement that was used in each beam. Compressive cube tests were conducted on concrete samples to obtain strength parameters during hardening and the mass density, and uniaxial tensile tests were performed on steel reinforcement samples to obtain relevant tensile strength parameters. 


\section{1}

\section{Concrete properties}

The concrete mass density and strength were determined through measurement, weighing and compressive testing of $150 \mathrm{~mm}$ cubes following the Swedish standard [16]. The results from the tests are summarized in Table 1. The first report shows the use of two concrete types since the beams were cast at different times, from different batches [7]. The second series of testing [8] used the same batch of concrete for all beams. The reason for the three concrete types in the third report [9] is that the authors wanted to investigate the effect of varying the concrete quality.

Table 1 - Concrete properties - compressive cube strength $\left(f_{c}\right)$ and average mass density.

\begin{tabular}{lccccc}
\hline Sample & $\begin{array}{c}\text { Age } \\
\text { (Days) }\end{array}$ & $f_{\mathrm{c}}(\mathrm{MPa})$ & $\begin{array}{c}\text { Standard } \\
\text { Deviation }(\mathrm{MPa})\end{array}$ & $\begin{array}{c}\text { Average mass } \\
\text { density }\left(\mathrm{kg} / \mathrm{m}^{3}\right)\end{array}$ & Test series \\
\hline 1 & 31 & 34.6 & 0,3 & 2275,9 & $1[7]$ \\
2. & 58 & 37.9 & 0,4 & 2267,8 & $2[8]$ \\
3 & 28 & 35.9 & 0,5 & 2285,6 & $2[8]$ \\
& 92 & 41.8 & 0,9 & 2271,5 & \\
4 & 28 & 47.8 & 0,7 & 2298,1 & $3[9]$ \\
5 & 152 & 52.8 & 0,4 & 2274,8 & $3[9]$ \\
& 29 & 42.3 & 0,6 & 2287,1 & \\
6 & 78 & 47.4 & 0,5 & 2274,7 & $3[9]$ \\
& 28 & 48.0 & 0,3 & 2364,0 & \\
\hline
\end{tabular}

\section{$2.2 \quad$ Reinforcement properties}

Three samples of each reinforcement quality were tested in uniaxial tensile tests, with the results summarized in Table 2 and Figures 1 and 2. The results from only one of the three samples are presented in the figures, but the reports $[7,8,9]$ showed small variability in the results of each reinforcement quality. The figures do not present the ultimate strain for any of the bars tested, since the sensors determining the strain came out of measurement range before rupture. The end of the line plots gives an indication of where this occurred. All bars used were ribbed, resulting in large interaction between the concrete and the reinforcement along their length.

Four different reinforcement qualities all with a bar diameter of $8 \mathrm{~mm}$ were tested in the first series [7]. These are compromised by an old mild steel quality (Ks40), an old stiff steel quality (Ps50) and two types of a newer steel quality (B500BT). The two B500BT types showed differences in the post-elastic region due to differences in the manufacturing process as seen in Figure 1 [7]. The type 1 reinforcement shows a distinct yield plateau while the type 2 reinforcement shows a consolidation region adjacent to the elastic region. The beams in the second test series [8] used the Ps50 and the B500BT type 1 reinforcements that were used in the first series. The third series [9] used a B500BT reinforcement with varying diameters $(6,8$ and 12 $\mathrm{mm}$ ). Figure 2 shows that the bars with a diameter of 6 and $8 \mathrm{~mm}$ showed consolidation adjacent to the elastic region similar to the stiff bars, while the bar with a diameter of $12 \mathrm{~mm}$ showed a distinct yield plateau similar to the mild bars. This occurs since the bars of small diameter are stored on rolls, and as the bars are unrolled and straightened they get partially cold worked. 


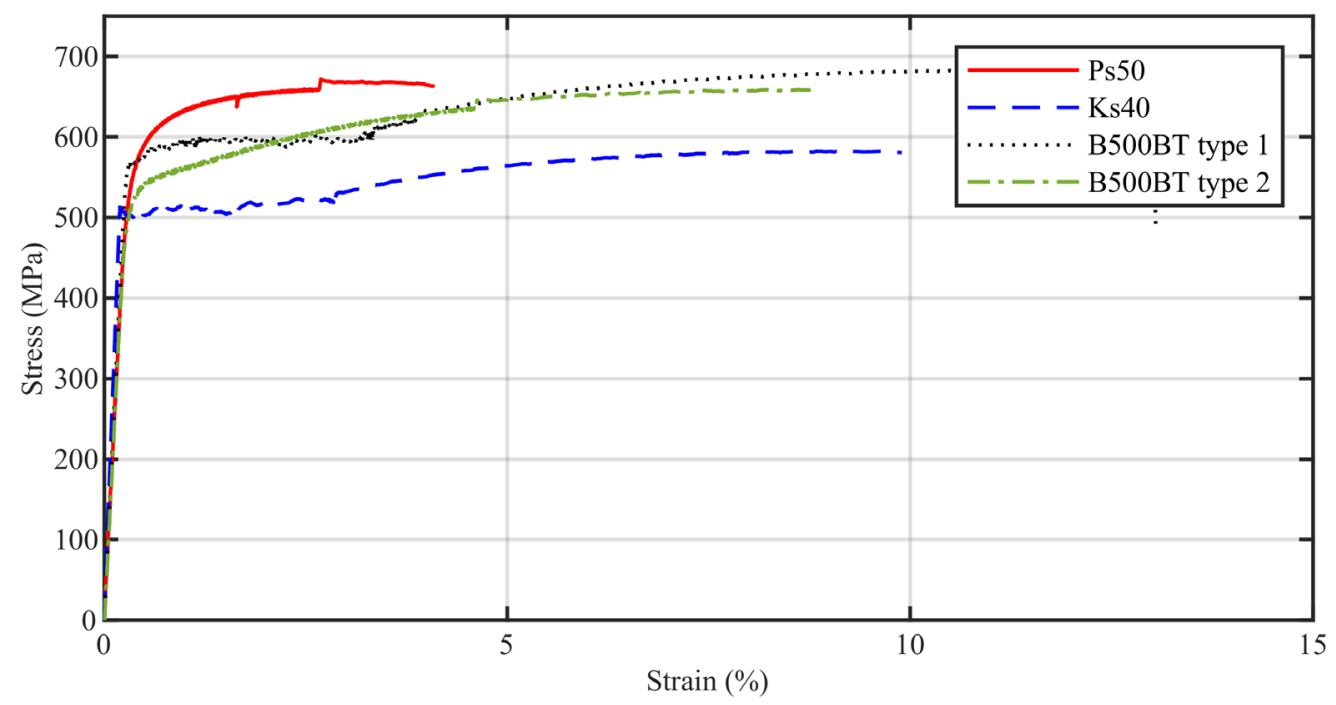

Figure 1 -Results from tensile tests in the first and second test series for each reinforcement quality $[7,8]$.

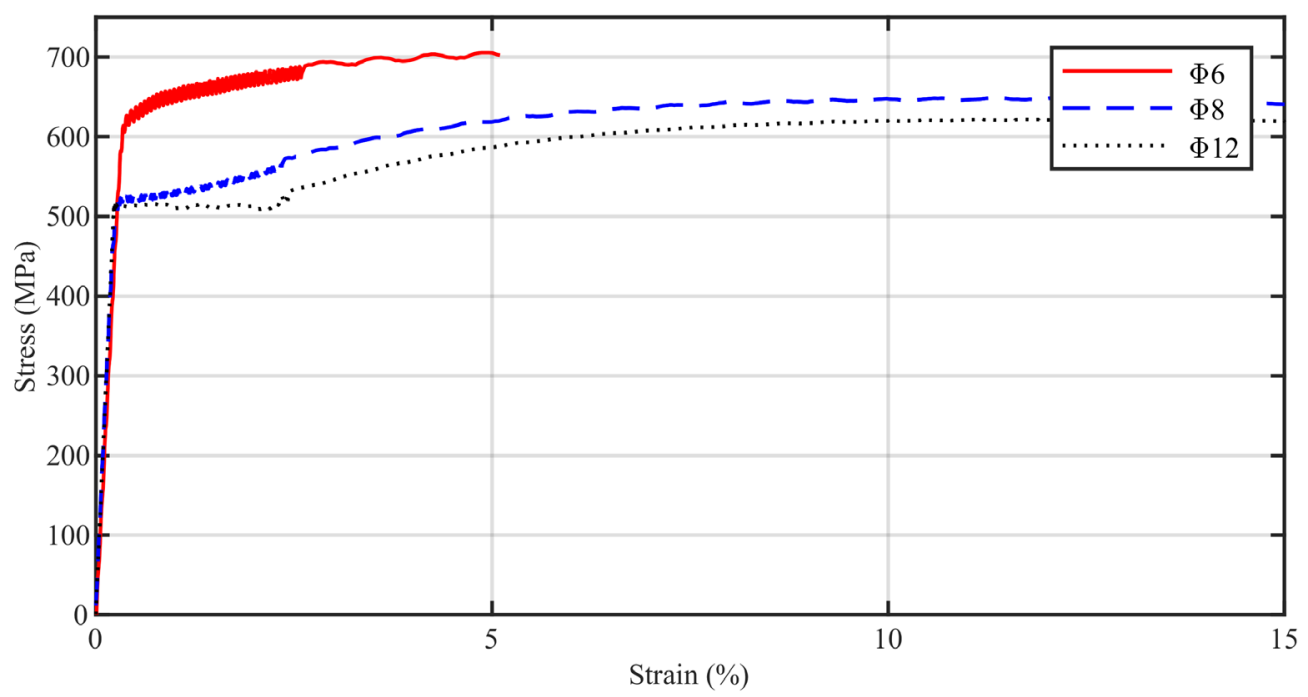

Figure 2-Results from tensile tests in the third test series for each diameter of the B500BT quality [9].

Table 2 - Reinforcement properties - yield strength $\left(f_{\mathrm{y}}\right)$, ultimate strength $\left(f_{\mathrm{u}}\right)$, ductility ratio and ultimate strain $\left(\varepsilon_{\mathrm{u}}\right)$.

\begin{tabular}{lcccccc}
\hline Type & $\begin{array}{c}\text { Diameter } \\
(\mathrm{mm})\end{array}$ & $f_{\mathrm{y}}(\mathrm{MPa})$ & $f_{\mathrm{u}}(\mathrm{MPa})$ & $\begin{array}{c}\text { Ductility ratio } \\
\left(f_{\mathrm{u}} / f_{\mathrm{y}}\right)\end{array}$ & $\varepsilon_{\mathrm{u}}(\%)$ & Test series \\
\hline Ks40 & 8 & 500 & 575 & 1.15 & $\mathrm{~N} / \mathrm{A}$ & $1[7]$ \\
B500BT type 1 & 8 & 570 & 660 & 1.16 & $\mathrm{~N} / \mathrm{A}$ & $1-2[7,8]$ \\
Ps50 & 8 & 560 & 665 & 1.19 & $\mathrm{~N} / \mathrm{A}$ & $1-2[7,8]$ \\
& & & & & & \\
B500BT type 2 & 8 & 540 & 660 & 1.22 & $\mathrm{~N} / \mathrm{A}$ & $1[7]$ \\
& & & & & & \\
B500BT & 6 & 580 & 690 & 1.19 & 18 & $3[9]$ \\
& 8 & 514 & 653 & 1.27 & 23 & $3[9]$ \\
& 12 & 516 & 624 & 1.21 & 28 & $3[9]$ \\
\hline
\end{tabular}




\section{EXPERIMENTAL TEST PROGRAM}

This section summarizes the experimental test set-ups and the beams tested. The dimensions were chosen such that the beam represented half-scale of slabs and walls found in Swedish fortifications $[7,8,9]$. The width and height of the cross-section of all beams were $300 \mathrm{~mm}$ and $150 \mathrm{~mm}$, respectively. The length between the pinned support and the roller was $1500 \mathrm{~mm}$, and an additional $200 \mathrm{~mm}$ overhang was used for anchorage of the reinforcement beyond each support resulting in a total length of $1900 \mathrm{~mm}$. The reinforcement was for all beams marked prior to casting with a spacing of $50 \mathrm{~mm}$ along the length. This allows for determining the average residual plastic strain of the $50 \mathrm{~mm}$ spans by measuring the elongation between the markings. The reports present results regarding displacement, cracking and the residual plastic strain.

The first series of tests [7] was performed to deduce the effect of the reinforcement quality during static loading. A similar concrete quality was used for all beams in the tests, and the reinforcement configuration was kept constant. The sole varying parameter was, thus, the reinforcement quality. Two reinforcement bars with a diameter of $8 \mathrm{~mm}$ and spacing of $150 \mathrm{~mm}$ were placed along the top and bottom of the beams, resulting in a reinforcement ratio of $0.22 \%$. The top reinforcement was placed close to the neutral layer and, thus, sustain negligible strain. The intention of the top reinforcement was purely practical; these bars made it easier to handle the beams after the experiment has finished. The second series of tests [8] was conducted to investigate the differences in the response from dynamic instead of static loading. Two reinforcement bars of 8 $\mathrm{mm}$ in diameter were placed along the top and bottom of the beam, as was done in the first series of tests. The old stiff steel (Ps50) and the new mild steel (B500BT type 1) tested in the first series of experiments were used.

The third series of tests [9] was conducted to test the effect several variables would have on the energy absorption capacity of reinforced concrete beams. The concrete quality was varied for static tests only. The reinforcement configuration was varied for both static and dynamic tests by maintaining the reinforcement area but changing the ratio of the area to the diameter. The configurations tested were $4 \phi 6,2 \phi 8$ and $1 \phi 12$, and they show an almost equivalent reinforcement area of 101-113 $\mathrm{mm}^{2}$ along the top and bottom edge. These configurations show a relation for the ratio of the area to the diameter of 3:4:6 $\mathrm{mm}$, respectively. It was hypothesized that a larger ratio, with a similar reinforcement area, implies that less surrounding concrete interacts with a similar force in the reinforcement, and, thus, shows a larger resemblance to the case of the free bar. The effect of the composite action on the plastic strain distribution can because of this be deduced. The drop height was varied to inquire the effect of variation of initial velocity on the plastic strain distribution, and to increase the work applied to the beam such that failure could be reached.

\section{1}

\section{Static test set-up}

The experimental test set-up for the static tests is presented in Figure 3. The reinforced concrete beam was simply supported with a rectangular cross-section. The experiment is displacementcontrolled in a monotonic quasi-static fashion to follow the equilibrium path until failure, and the displacement is applied through a hydraulic piston to a relatively stiff steel HEB-beam as indicated by the black arrow. The steel beam in turn applies the displacement equally at one-third and twothirds of the concrete beam's length. The test set-up resembles a four-point flexural test, which results in the part of the concrete beam spanning the supports of the HEB beam showing constant internal moments and no shear forces. This set-up is used to guide the concrete beam towards flexural failure modes. 
The dynamic experimental set-up shown in Figure 4 was based on identical boundary conditions, geometrical characteristics and positions for load application as for the static set-up. The dynamic test applied deformation work to the beam by dropping a mass from a height that has been calculated to result in an impact velocity of $2 \mathrm{~m} / \mathrm{s}$. [8,9]. The mass to be dropped was determined through analytical calculation based on the premise that its potential energy would result in the same deflection as for the analogous static case for one of the beams with a B500BT reinforcement quality. The conclusion was a $300 \mathrm{~kg}$ mass element, and the mass remained constant during all subsequent tests $[8,9]$. In case the beam did not reach its energy absorption capacity the height of the drop was increased to reach higher potential energy that can be absorbed by the concrete beam. The mass was dropped on a dampening wood fibreboard, which through a HEA-beam transfer the momentum of the collision to the concrete beam at one-third and two-thirds of the length. The report [9] showed possible plastic straining in the fibreboard or the steel beam as the impact was deemed plastic, thus implying an additional energy dissipating mechanism which differed from the static tests.

\section{3}

\section{Test series}

Table 3 presents a summary of the beams tested $[7,8,9]$. Thirty tests were performed between the three test series, and five parameters were varied; concrete quality, reinforcement quality, test type, reinforcement configuration and drop height.

Table 3 - Summary of tested beams.

\begin{tabular}{lccccc}
\hline Beam & $\begin{array}{c}\text { Concrete cube } \\
\text { samples }\end{array}$ & $\begin{array}{c}\text { Reinforcement } \\
\text { quality }\end{array}$ & $\begin{array}{c}\text { Reinforcement } \\
\text { configuration }(\mathrm{mm})\end{array}$ & $\begin{array}{c}\text { Drop height } \\
(\mathrm{mm})\end{array}$ & $\begin{array}{c}\text { Test } \\
\text { series }\end{array}$ \\
\hline $1-3$ & 1 & Ks40 & $2 \phi 8$ & Static test & $1[7]$ \\
$4-6$ & 1 & B5005BT type 1 & $2 \phi 8$ & Static test & $1[7]$ \\
$7-9$ & 2 & Ps50 & $2 \phi 8$ & Static test & $1[7]$ \\
$10-12$ & 2 & B5005BT type 2 & $2 \phi 8$ & Static test & $1[7]$ \\
$13-15$ & 3 & Ps50 & $2 \phi 8$ & 400 & $2[8]$ \\
16 & 3 & Ps50 & $2 \phi 8$ & 200 & $2[8]$ \\
$17-19$ & 3 & B5005BT type 1 & $2 \phi 8$ & 400 & $2[8]$ \\
20 & 3 & B5005BT type 1 & $2 \phi 8$ & 800 & $2[8]$ \\
21 & 4 & B5005BT & $4 \phi 6$ & Static test & $3[9]$ \\
22 & 4 & B5005BT & $1 \phi 12$ & Static test & $3[9]$ \\
23 & 5 & B5005BT & $2 \phi 8$ & Static test & $3[9]$ \\
24 & 6 & B5005BT & $2 \phi 8$ & Static test & $3[9]$ \\
25 & 4 & B5005BT & $4 \phi 6$ & 400 & $3[9]$ \\
$26-27$ & 4 & B5005BT & $4 \phi 6$ & 800 & $3[9]$ \\
28 & 4 & B5005BT & $1 \phi 12$ & 400 & $3[9]$ \\
29 & 4 & B5005BT & $1 \phi 12$ & 800 & $3[9]$ \\
30 & 4 & B5005BT & $1 \phi 12$ & 1150 & $3[9]$ \\
\hline
\end{tabular}




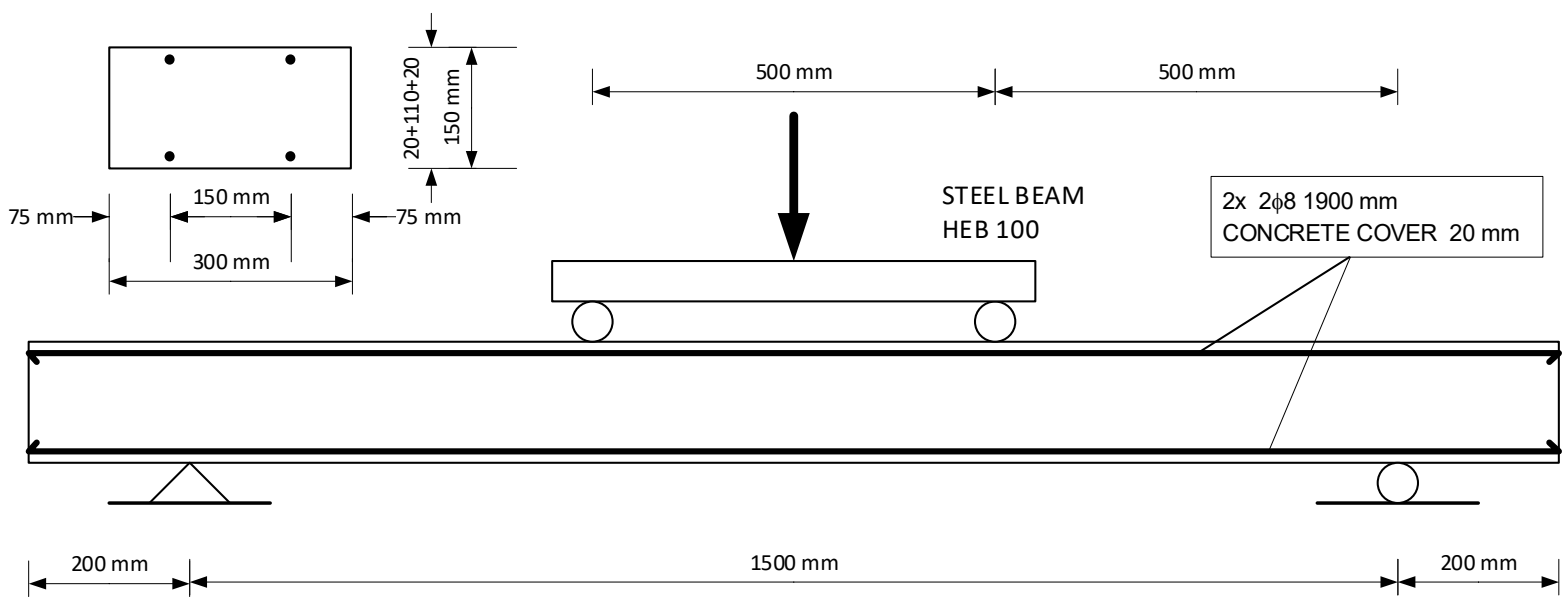

Figure 3 - Experimental set-up for static tests of the $2 \phi 8$ reinforcement configuration (redrawn from $[7,8])$.

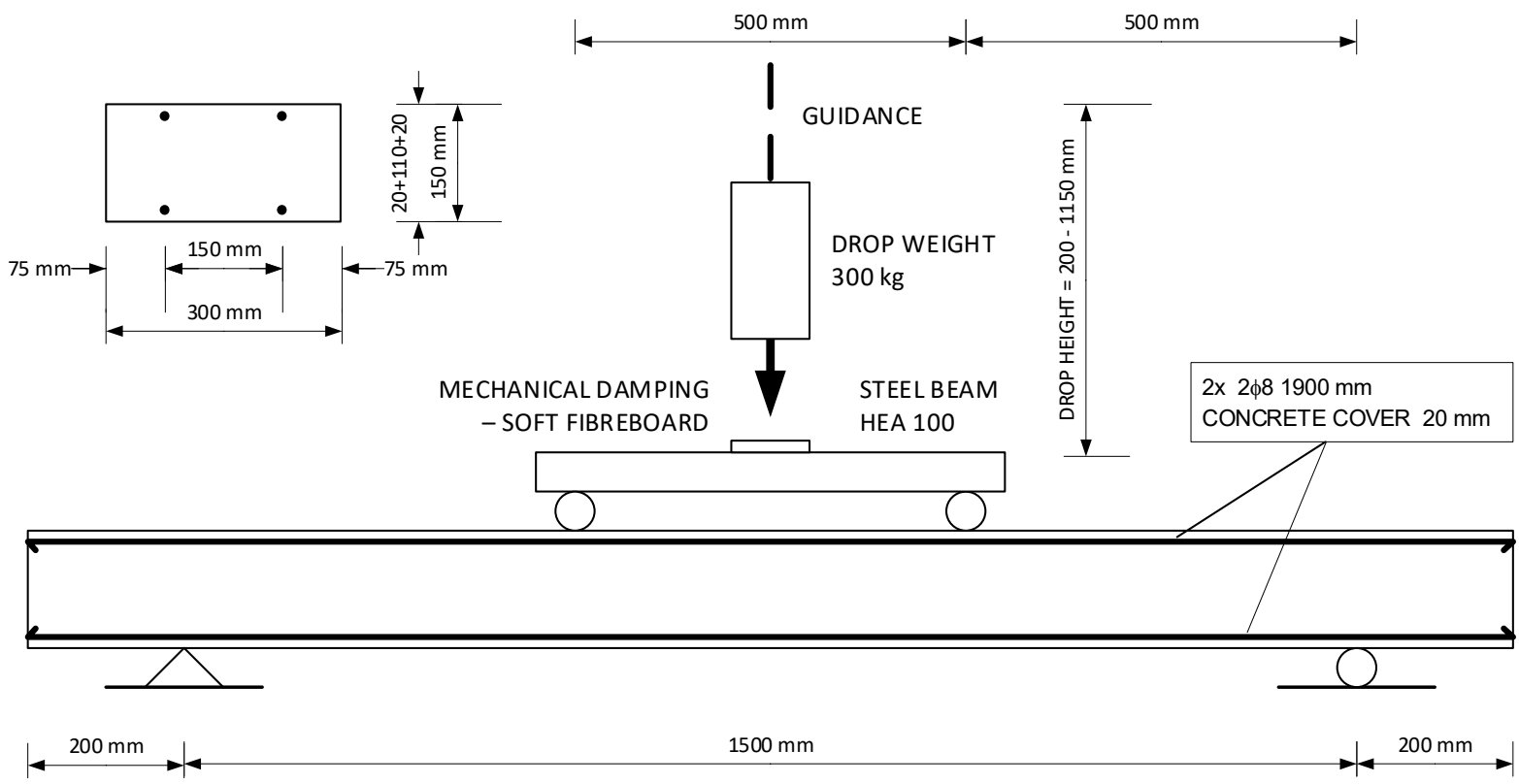

Figure 4 - Experimental set-up for dynamic tests of the $2 \phi 8$ reinforcement configuration (redrawn from [9]).

4. RESULTS AND DISCUSSION

The tests aimed to evaluate the energy absorption capacity of reinforced concrete beams as parameters were varied, and a secondary goal was to investigate to what extent results from tests using static loading can be extrapolated to cases of impulsive loading. The results compared for each beam are the plastic strain distribution and the absorbed energy of the reinforcement bars. The energy absorbed by a reinforcement bar can be determined by integrating the area of the hysteresis loop found in the stress-strain diagrams over the volume as the beam has been unloaded or the motion has ended depending on the type of loading [17]. Thus, a comparative amount of energy absorbed by the reinforcement bars can be determined following Eq. (1), as was done in the report of the third test series [9]. This energy only considers the part absorbed by the reinforcement, with the energy absorbed by the concrete from fracture or internal friction not considered. Energy absorbed by the fibreboard and steel beam at impact was also disregarded. 
$W_{\mathrm{p}}=\sum_{\mathrm{i}} \varepsilon_{\mathrm{i}} \times A_{\mathrm{s}} \times f_{\mathrm{u}}$

where:

$W_{\mathrm{p}}=$ comparative amount of the absorbed plastic strain energy

$\varepsilon_{\mathrm{i}}=$ average plastic strain for $50 \mathrm{~mm}$ span $\mathrm{i}$

$A_{\mathrm{s}}=$ reinforcement area

$f_{\mathrm{u}}=$ ultimate tensile strength of the reinforcement

The reports of the three test series $[7,8,9]$ present the plastic strain distribution for all bars in the bottom layer of the $2 \phi 8$ and the $4 \phi 6$ configuration. For visibility, the figures in the following sections instead show the results for only one of the bars of the bottom layer. The three reports also present the plastic strain distributions for each beam individually in the form of bar charts which adequately represent the physical interpretation of the results. The following figures will present the same value as the bar charts in the middle of each $50 \mathrm{~mm}$ span, but linear interpolation will be used for values between the middle of each span. This results in line plots rather than bar charts and is performed for visibility as the results of several beams will be presented in each figure. It is, however, noted that this way of presenting the results does not represent physical behaviour as well.

\subsection{Concrete quality}

By comparing the results for beam 23 and 24 the effect of an increased concrete quality during static loading can be deduced. The sole varying parameter between these beams is the concrete quality, and the beams showed a 28-day compressive cube strength of approximately 48 and 101 $\mathrm{MPa}$, respectively. Even though the compressive cube strength has more than doubled, the results in Figure 5 show negligible differences in the plastic strain distribution. The results in Table 4 furthermore shows that the concrete quality does not have a large effect on the energy absorption capacity of the reinforcement; a circa $10 \%$ increase in the comparative amount of absorbed energy occurs as the compressive strength of the concrete is doubled. The effect of the concrete quality during highly impulsive loading could, however, differ, as strain rate and inertia effects could increase this difference further as shown in e.g. [18]. It should be noted that the low reinforcement ratio in the studied beams results in few and sparse cracks, and for cases showing smaller crack spacing the same conclusions may not apply.

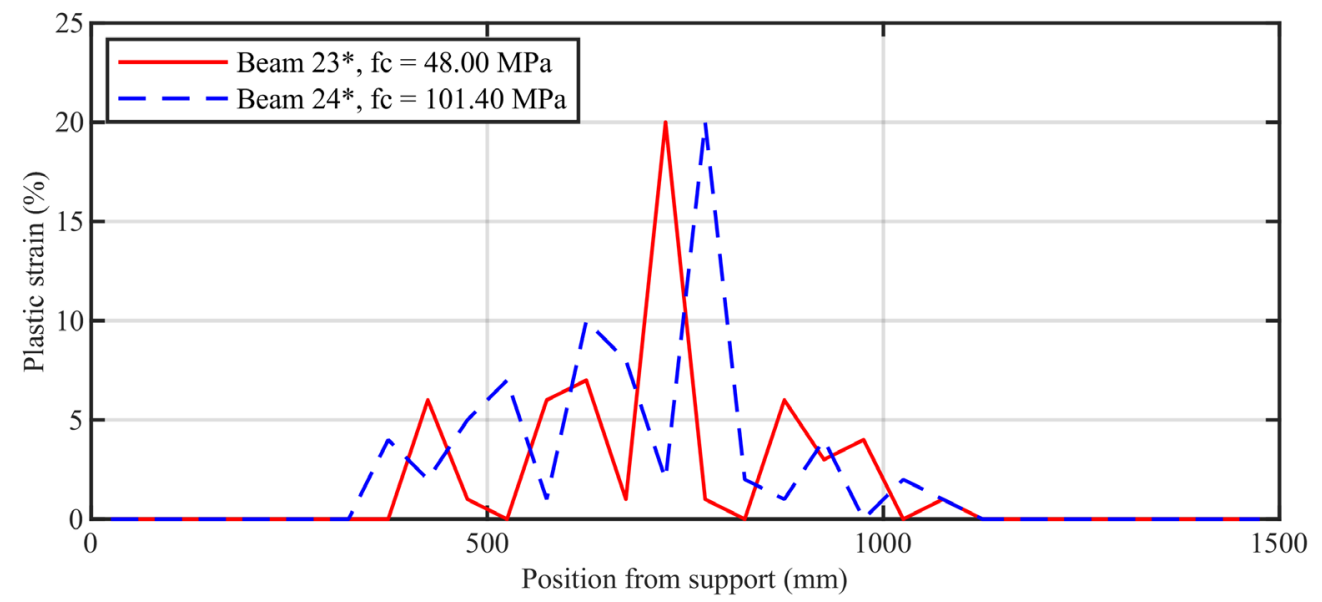

Figure 5 - Plastic strain distribution for beams of various concrete strength during static loading (* indicates rupture of the reinforcement). 
Table 4-Absorbed energy of one of the reinforcement bars for beams of various concrete strength during static loading.

\begin{tabular}{lccccc}
\hline Beam & $f_{\mathrm{c}}(\mathrm{MPa})$ & $A_{\mathrm{s}}\left(\mathrm{mm}^{2}\right)$ & $f_{\mathrm{u}}(\mathrm{MPa})$ & $\sum_{\mathrm{i}} \varepsilon_{\mathrm{i}}(\%)$ & $W_{\mathrm{p}}(\mathrm{Nm} / \mathrm{mm})$ \\
\hline $23^{*}$ & 48 & 50.2 & 653 & 112 & 3671 \\
$24^{*}$ & 101.4 & 50.2 & 653 & 124 & 4032 \\
\hline
\end{tabular}

* Indicates rupture of the reinforcement

\subsection{Reinforcement quality}

If beams 1-12 are compared, the sole varying parameter is the reinforcement quality during static loading, and if beams 13-20 are compared the varying parameters are reinforcement quality and drop height during dynamic loading. The dynamic tests required the drop height to also vary to reach failure of both reinforcement qualities compared. The energy absorption capacity of the reinforcement cannot be determined if the reinforcement has not ruptured.

Results during static loading are first presented in Figure 6. Instead of showing all beams with similar material and loading properties, which is the case for beams 1-3 for instance, only one representative beam is presented and the result of the other beams are instead given in the Appendix. Studying the figure it can be observed that beams 3 and 6 show less localization of the plastic strain towards the beam mid-point in comparison to beams 7 and 10 . The main difference between the bars is the constitutive behaviour. While the Ks40 and B500BT type 1 reinforcement bars used in beams 1-6 showed a distinct yield plateau in the tensile tests presented in Figure 1, the Ps50 and B500BT type 2 used in beams 7-12 instead showed a consolidation region adjacent to the elastic region. This indicates that the yield plateau is important for a favourable plastic strain distribution as less localization generally results in more total energy absorbed before local rupture of the reinforcement at the point of strain localization. The reason for the favourable distribution of the mild steels is the stiffening occurring as the strain level reaches the consolidation region after going through the yield plateau. This allows for the yield zone to spread adjacent to the stiffened positions [19].

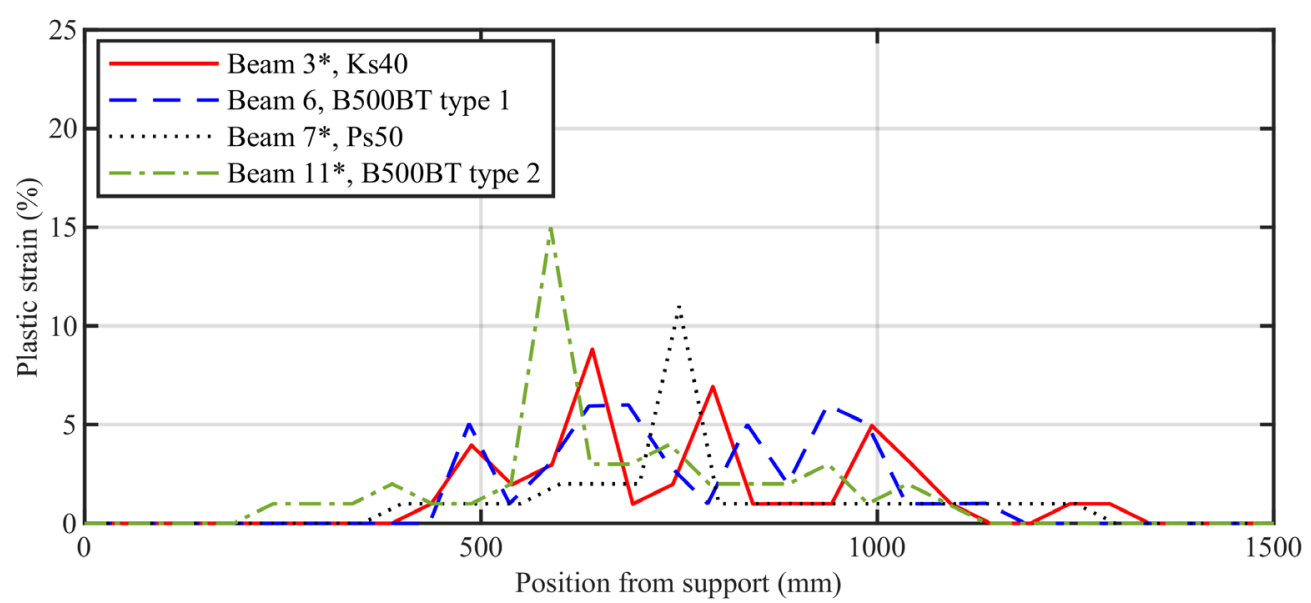

Figure 6 -Plastic strain distribution for beams with varying reinforcement qualities during static loading (*indicates rupture of the reinforcement).

Table 5 presents a comparison of the absorbed energy during static loading. The first interesting observation that can be made is the difference in the energy absorption capacity of beams 3 and 7. While the ultimate strength is significantly larger for the stiff Ps50 steel found in beam 7 due 
to cold working during manufacturing, it still performs worse during impulsive loading as shown by its lower energy absorption capacity. This since the strain distribution of beam 7 showed a larger degree of strain localization in Figure 6 in combination with its lower strain capacity. The decreased strain capacity of the stiff Ps50 steel is stressed by the test results presented in Table 2 where the ultimate strain capacity $\left(\varepsilon_{\mathrm{u}}\right)$ is $10 \%$ lower for the cold worked $\phi 6$ bar in comparison to the mild $\phi 12$ bar which are analogous to the Ps50 and Ks40 bars, respectively. The second interesting observation is the large energy absorption capacity of the newer B500BT type 2 reinforcement in beam 11 in comparison to beam 3, where beam 11 showed strain localization in Figure 6 which beam 3 did not. This indicates that the constitutive behaviour is not the sole governing factor for the energy absorption capacity and that other tensile properties such as strain capacity and ultimate strength also show significant importance.

Table 5 -Absorbed energy of one of the reinforcement bars for beams with varying reinforcement qualities during static loading.

\begin{tabular}{lcccc}
\hline Beam & $A_{\mathrm{s}}\left(\mathrm{mm}^{2}\right)$ & $f_{\mathrm{u}}(\mathrm{MPa})$ & $\sum_{\mathrm{i}} \varepsilon_{\mathrm{i}}(\%)$ & $W_{\mathrm{p}}(\mathrm{Nm} / \mathrm{mm})$ \\
\hline $3^{*}($ Ks40) & 50.2 & 575 & 79 & 2267 \\
$7^{*}($ Ps50) & 50.2 & 665 & 54 & 1802 \\
$11^{*}($ B500BT type 2$)$ & 50.2 & 660 & 102 & 3379 \\
\hline
\end{tabular}

* Indicates rupture of the reinforcement

The results for beams 13-20 sustaining work from dynamic loading are presented in Figure 7. If comparing beams 15 and 20, both show a large degree of strain localization towards the beam mid-point even though beam 20 used mild steel and beam 15 used stiff steel. This indicates that the effect of the reinforcement configuration is not as prominent when the beam is subjected to dynamic loading. However, if comparing beams 16 and 19 subjected to decreased drop heights it can be observed that the stiff steel used in beam 16 results in a large degree of localization, which is not the case for beam 19 with mild steel. The reinforcement quality is for these drop heights shown to have a significant effect on the plastic strain distribution.

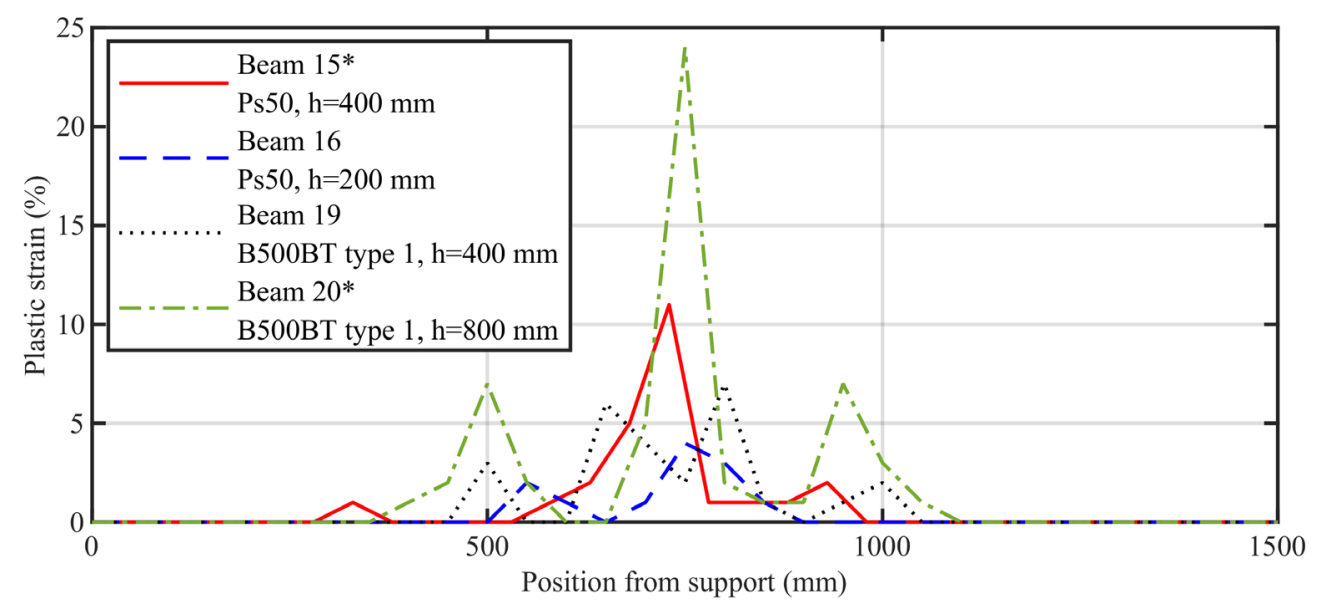

Figure 7 - Plastic strain distribution for beams with varying reinforcement qualities during dynamic loading with various drop heights (* indicates rupture of the reinforcement).

The results in terms of comparative amounts of absorbed energy are presented in Table 6 , for the case of dynamic loading. The table shows that beam 20 has absorbed more energy at the point of rupture when compared to beam 15 . This means that the energy absorption capacity is increased for mild steels and that this is a result of other parameters than the shape of the stress-strain curve as both beams showed strain localization in Figure 7. 
Table 6 - Absorbed energy of one of the reinforcement bars for beams with varying reinforcement qualities during dynamic loading.

\begin{tabular}{lccccc}
\hline Beam & Drop height $(\mathrm{mm})$ & $A_{\mathrm{s}}\left(\mathrm{mm}^{2}\right)$ & $f_{\mathrm{u}}(\mathrm{MPa})$ & $\sum_{\mathrm{i}} \varepsilon_{\mathrm{i}}(\%)$ & $W_{\mathrm{p}}(\mathrm{Nm} / \mathrm{mm})$ \\
\hline $15^{*}(\mathrm{Ps} 50)$ & 400 & 50.2 & 665 & 46 & 1535 \\
$20^{*}($ B500BT type 1$)$ & 800 & 50.2 & 660 & 109 & 3611 \\
\hline
\end{tabular}

* Indicates rupture of the reinforcement

This section compares the implications of subjecting the beam to a dynamic rather than static loading. This is done by comparing the results from the first [7] and second [8] test series. These beams showed a slight variation in the concrete quality; while the beams in the first series showed a 28-day strength of approximately $36 \mathrm{MPa}$, the beams in the second series showed the same strength of $46 \mathrm{MPa}$. It was, however, shown in Section 4.1 that almost doubling the concrete strength resulted in small differences in the plastic strain distribution and the energy absorption capacity. The difference in concrete quality is because of this disregarded, and the variable resulting in the difference of the behaviour is deemed to be the loading type.

Beam 6 subjected to static loading is first compared with beam 19 subjected to a drop height of $400 \mathrm{~mm}$ in Figure 8, and both beams contain a B500BT type 1 reinforcement quality. The results show a distribution with a small degree of localization for both beams. This indicates that beams containing mild steel subjected to small impact velocities show similar behaviour when compared to equivalent static tests. However, beam 20 in the same figure, subjected to an increased drop height of $800 \mathrm{~mm}$, instead shows a large degree of localization of the strain towards the centre of the beam. This means that mild steel can show positions of large strain localization during dynamic loading which disagrees with the findings during static loading. The energy absorption capacity cannot be compared as it is difficult to say how much energy absorption capacity was left at the point of unloading during the static test which was not deformed to failure.

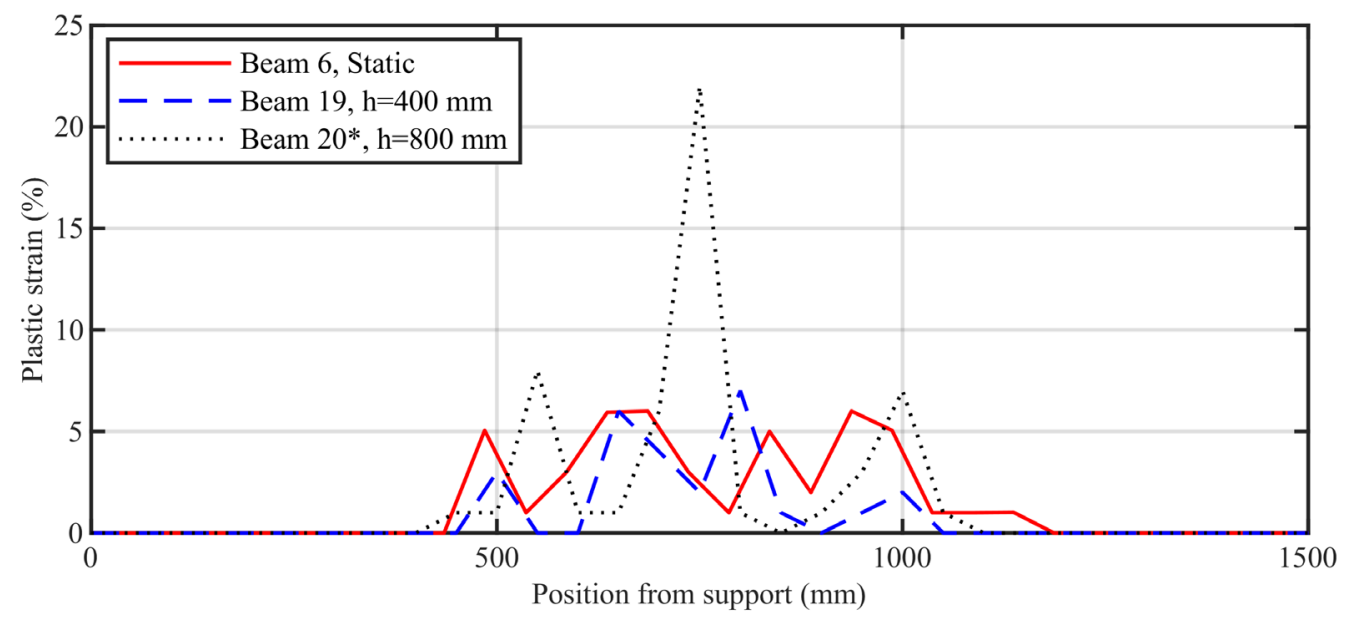

Figure 8-Plastic strain distribution for beams using B500BT type 1 reinforcement quality during dynamic and static loading (* indicates rupture of the reinforcement).

Figure 9 presents the plastic strain distribution for beams containing the old stiff steel (Ps50) during dynamic and static loading. The results seem to agree well; a large degree of strain localization occurs during both dynamic and static loading. Table 7, furthermore, shows that the 
energy absorption capacity of beams 7 and 15 during static and dynamic loading agree. Results during static tests for beams containing stiff steels seem as such to apply to cases of dynamic loading. Further investigation regarding how the results are affected by an increased impact velocity is, however, of interest.

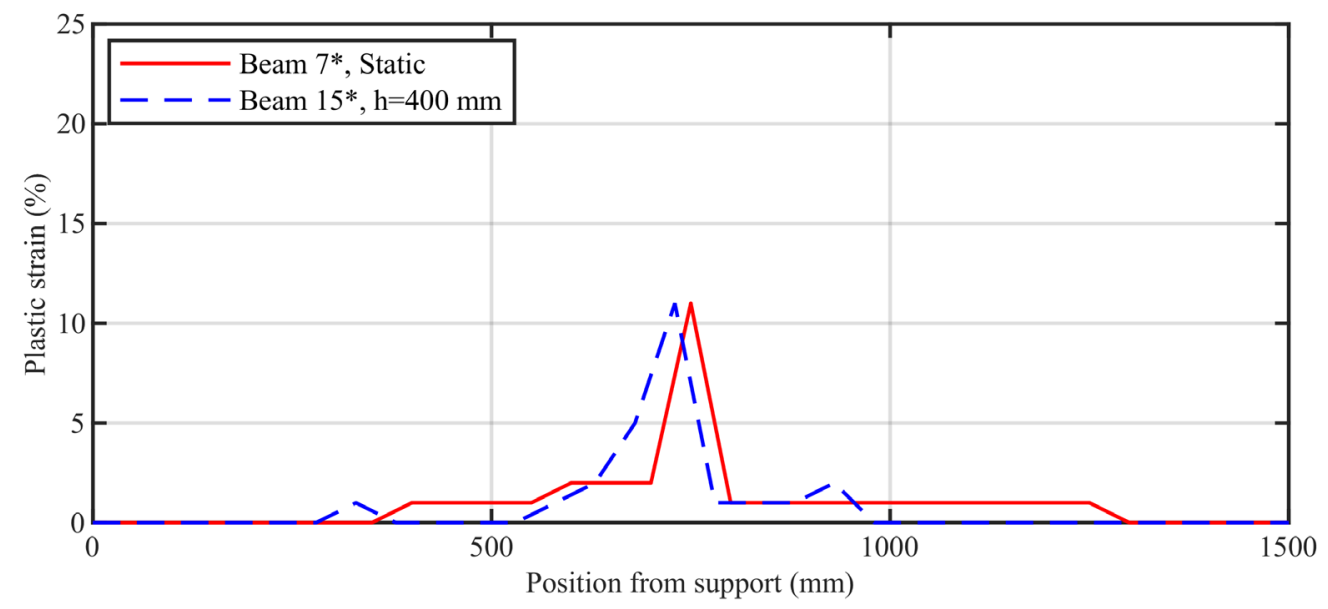

Figure 9 - Plastic strain distribution for beams using the Ps50 reinforcement quality during dynamic and static loading (* indicates rupture of the reinforcement).

Table 7 - Absorbed energy of one of the reinforcement bars for beams using the Ps50 reinforcement quality during dynamic and static loading.

\begin{tabular}{lccccc}
\hline Beam & $\begin{array}{c}\text { Drop height } \\
(\mathrm{mm})\end{array}$ & $A_{\mathrm{s}}\left(\mathrm{mm}^{2}\right)$ & $f_{\mathrm{u}}(\mathrm{MPa})$ & $\sum_{\mathrm{i}} \varepsilon_{\mathrm{i}}(\%)$ & $W_{\mathrm{p}}(\mathrm{Nm} / \mathrm{mm})$ \\
\hline $7^{*}$ & Static & 50.2 & 665 & 54 & 1802 \\
$15^{*}$ & 400 & 50.2 & 665 & 46 & 1535 \\
\hline
\end{tabular}

* Indicates rupture of the reinforcement

\subsection{Reinforcement configuration}

The third report [9] had an aim to investigate the effect of the composite action on the plastic strain distribution and the energy absorption capacity. This was done through variation of the ratio of the area to the diameter, where a smaller ratio implies more composite action as explained in Section 3. Figure 10 shows the results during static action. Even though beams 21 and 22 used reinforcement from the same manufacturer their bars still showed significant differences in their constitutive behaviour as the diameter was increased as presented in Figure 2. For this reason, beam 21 is compared to beam 11 only since the reinforcement of both beams showed a similar behaviour after the elastic region characterized by an instant consolidation region. This reduces the number of varying parameters to only the reinforcement configuration. For the same reason, beam 22 is only compared to beam 6; their reinforcement showed a distinct yield plateau in the post-elastic region.

The results of beams 21 and 11 in the figure show a similar plastic strain distribution. The strain is localized to a high degree at the beam mid-point, but the amplitude of beam 11 is significantly larger due to differences in strain capacity. Comparing the results of beams 22 and 6 they also show a similar distribution, however, instead characterized by a low degree of localization. This indicates that composite action does not have a large influence on the plastic strain distribution in comparison to other variables. 


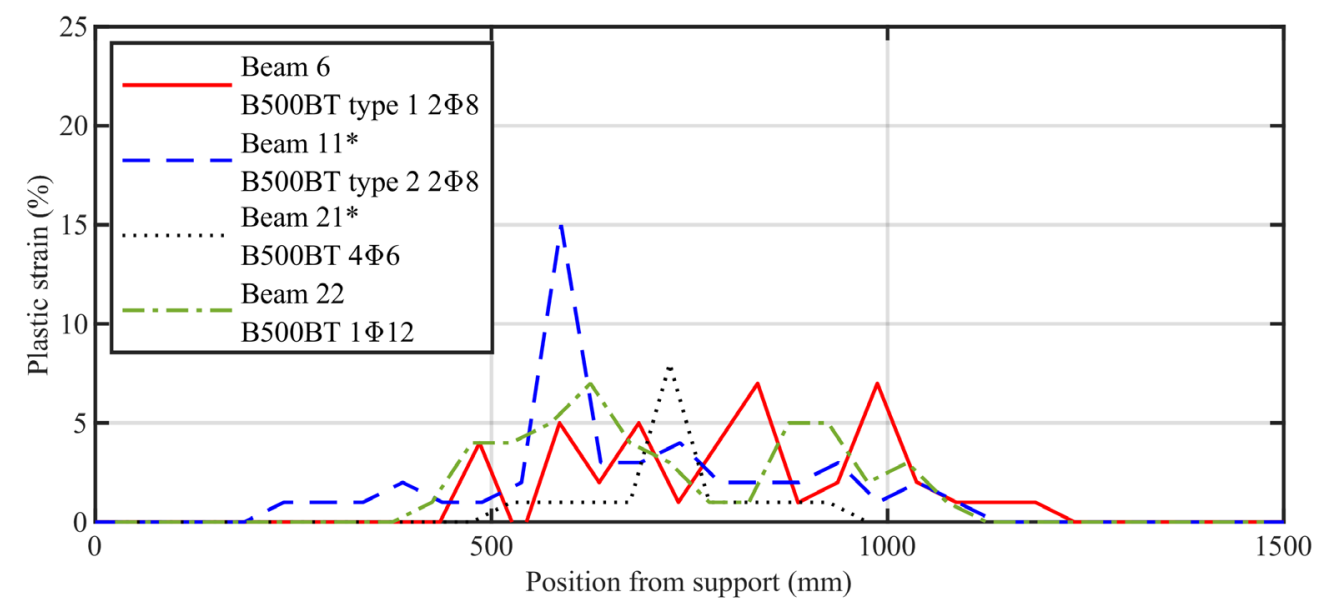

Figure 10 - Plastic strain distribution for beams with different reinforcement configurations during static testing (* indicates rupture of the reinforcement).

Table 8 presents the comparative amount of absorbed energy of the beams during static loading. Beam 11 shows a larger energy absorption capacity in comparison to beam 21, which uses a smaller diameter. Furthermore, beam 22 has not yet reached rupture with an absorbed energy that is almost equivalent to the energy absorption capacity of beam 11 , which uses a smaller reinforcement diameter. Both comparisons indicate that an increasing diameter also increases the energy absorption capacity. The decreased composite action possibly result in the improvement.

Table 8-Absorbed energy of one of the reinforcement bars for beams with different reinforcement configurations during static testing.

\begin{tabular}{|c|c|c|c|c|c|}
\hline Beam & $\begin{array}{l}\text { Relation in ratio of area } \\
\text { to diameter }(\mathrm{mm})\end{array}$ & $A_{\mathrm{s}}\left(\mathrm{mm}^{2}\right)$ & $f_{\mathrm{u}}(\mathrm{MPa})$ & $\sum_{\mathrm{i}} \varepsilon_{\mathrm{i}}(\%)$ & $W_{\mathrm{p}}(\mathrm{Nm} / \mathrm{mm})$ \\
\hline $11 *(\mathrm{~B} 500 \mathrm{BT}$ type $22 \phi 8)$ & 4 & 50.2 & 660 & 102 & 3379 \\
\hline $21 *(\mathrm{~B} 500 \mathrm{BT} 4 \phi 6)$ & 3 & 28.3 & 690 & 60 & 1172 \\
\hline 22 (B500BT $1 \phi 12)$ & 6 & 113 & 624 & 46 & 3244 \\
\hline
\end{tabular}

* Indicates rupture of the reinforcement

Figure 11 compares the plastic strain distribution during dynamic loading for various reinforcement configurations subjected to a drop height of $800 \mathrm{~mm}$. All three beams show a large degree of strain localization towards the centre. It seems like the plastic strain distribution is not affected to a large extent from a larger composite action since beam 29, using the largest reinforcement diameter, would have shown larger differences when compared to beams 20 and 27 if so were the case.

Table 9 presents the relatively low energy absorption capacity of beam 27 with a $4 \phi 6$ configuration in comparison to beam 20 with a $2 \phi 8$ configuration. This is, however, assumed to mainly be a result of the reduced strain capacity of the $4 \phi 6$ reinforcement presented in Table 2 rather than an effect of the reinforcement configuration. Furthermore, beam 30 has not yet failed and contains a larger amount of absorbed energy in comparison to beam 20, which indicates that the energy capacity is increased with an increasing diameter of the reinforcement. This was also found for the static case in Table 8. Comparing beams 20 to 29, it can be observed that significantly less energy is stored within the reinforcement with a larger ratio of area to diameter for the same drop height. 


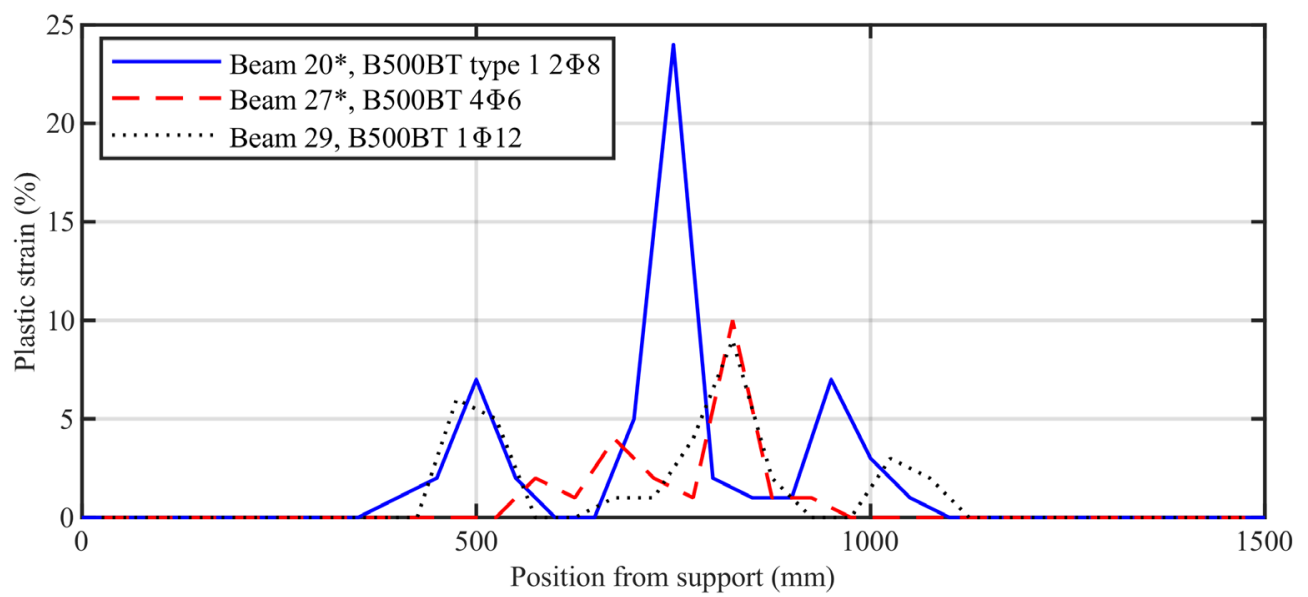

Figure 11 - Plastic strain distribution for beams with different reinforcement configurations during dynamic testing with a drop height of $800 \mathrm{~mm}$ (*indicates rupture of the reinforcement).

Table 9-Absorbed energy of one of the reinforcement bars for beams with different reinforcement configurations during dynamic testing.

\begin{tabular}{|c|c|c|c|c|c|c|}
\hline Beam & $\begin{array}{l}\text { Drop } \\
\text { height } \\
(\mathrm{mm}) \\
\end{array}$ & $\begin{array}{c}\text { Relation in ratio } \\
\text { of area to } \\
\text { diameter }(\mathrm{mm})\end{array}$ & $A_{\mathrm{s}}\left(\mathrm{mm}^{2}\right)$ & $f_{\mathrm{u}}(\mathrm{MPa})$ & $\begin{array}{l}\sum_{\mathrm{i}} \varepsilon_{\mathrm{i}} \\
(\%)\end{array}$ & $\begin{array}{c}W_{\mathrm{p}} \\
(\mathrm{Nm} / \mathrm{mm})\end{array}$ \\
\hline $20 *($ B500BT type $12 \phi 8)$ & 800 & 4 & 50.2 & 660 & 109 & 3611 \\
\hline $27 *(\mathrm{~B} 500 \mathrm{BT} 4 \phi 6)$ & 800 & 3 & 28.3 & 690 & 76 & 1482 \\
\hline 29 (B500BT 1ф12) & 800 & 6 & 113 & 624 & 33 & 2329 \\
\hline 30 (B500BT 1ф12) & 1150 & 6 & 113 & 624 & 52 & 3670 \\
\hline
\end{tabular}

* Indicates rupture of the reinforcement

Figure 12 shows results for the various reinforcement configurations during dynamic loading before failure of the beams, and subjected to a drop height of $400 \mathrm{~mm}$. The figure shows a similar plastic strain distribution for all three beams, and how the reinforcement configuration does not have a large influence on the plastic strain distribution.

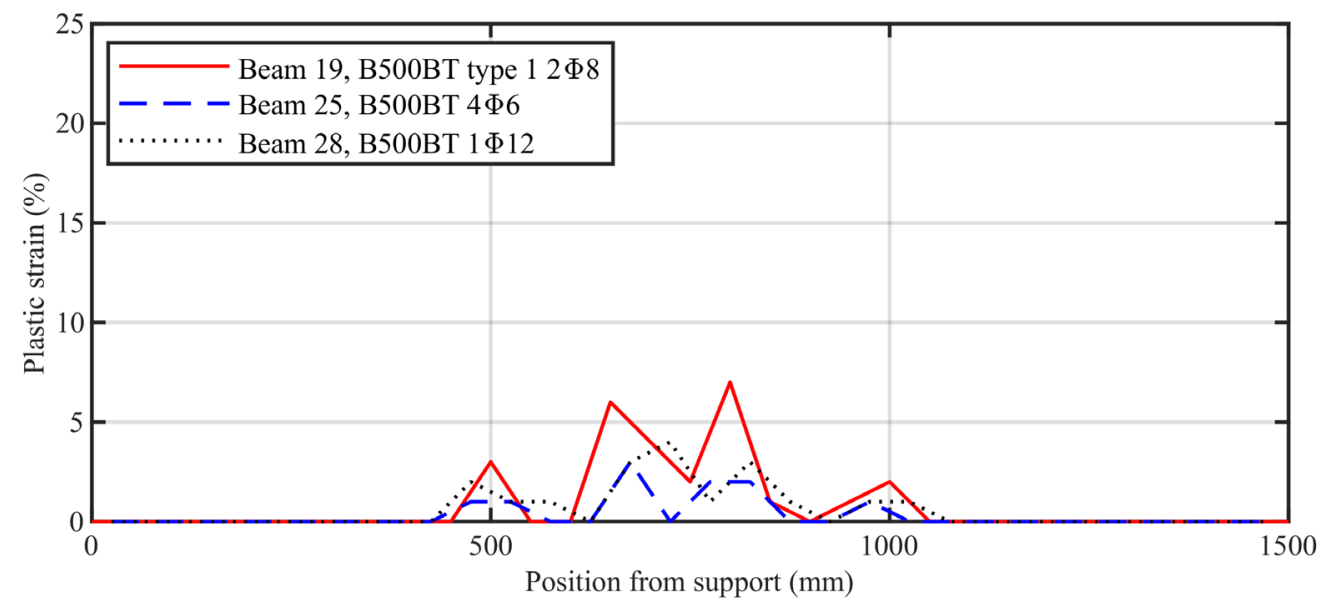

Figure 12 - Plastic strain distribution for beams with different reinforcement configurations during dynamic testing with a drop height of $400 \mathrm{~mm}$.

Table 10 shows the absorbed energy of reinforcement configurations subjected to the same drop height where none of the reinforcement bars ruptured. Beams 19 and 28 containing reinforcement bars with similar post-elastic region behaviour is first compared. This comparison shows that the reinforcement in beam 19, with less degree of composite action, absorbs more of the potential 
energy of the dropped mass. This was also shown for the case of a larger drop height in Table 9. Comparing beams 19 and 25, where the reinforcement quality also is a variable due to the large differences between them, it is instead the beam with a higher degree of composite action (beam 25 ) that absorbs more of the potential energy in the reinforcement. This indicates that the tensile properties of the reinforcement also play a large role in the amount of the potential energy of the mass that is absorbed by the reinforcement.

Table 10 - Absorbed energy of one of the reinforcement bars for beams with different reinforcement configurations during dynamic loading with a drop height of $400 \mathrm{~mm}$.

\begin{tabular}{|c|c|c|c|c|c|}
\hline Beam & $\begin{array}{l}\text { Relation in ratio of area } \\
\text { to diameter }(\mathrm{mm})\end{array}$ & $A_{\mathrm{s}}\left(\mathrm{mm}^{2}\right)$ & $f_{\mathrm{u}}(\mathrm{MPa})$ & $\sum_{\mathrm{i}} \varepsilon_{\mathrm{i}}(\%)$ & $\begin{array}{c}W_{\mathrm{p}} \\
(\mathrm{Nm} / \mathrm{mm})\end{array}$ \\
\hline 19 (B500BT type $12 \phi 8)$ & 4 & 50.2 & 660 & 53 & 1769 \\
\hline 25 (B500BT 4ф6) & 3 & 28.3 & 690 & 34 & 663 \\
\hline 28 (B500BT 1ф12) & 6 & 113 & 624 & 18 & 1270 \\
\hline
\end{tabular}

The sole difference between the beams in this section is the drop height of the mass. An increased drop height has two implications according to the reports [8,9]; it increases the potential energy of the mass that can be absorbed by the beams, and it increases the impact velocity of the collision as the mass accelerates during the time of its falling motion. The variation of the impact velocity in turn affects the plastic and elastic stress wave propagation, as explained in e.g. [20,21]. Each reinforcement configuration is discussed separately in each figure to reduce the number of varying parameters. Four drop heights were tested; 200, 400, 800 and $1150 \mathrm{~mm}$, and these correspond to impact velocities of $1.98,2.80,3.96$ and $4.75 \mathrm{~m} / \mathrm{s}$, respectively.

Figure 13 shows that both impact velocities result in strain localization at the points of momentum transfer from the steel beam to the concrete beam, which occurs at 500 and $1000 \mathrm{~mm}$ from the left-most support. The difference that can be observed is that the lower impact velocity results in less localized strain in the span between the points of the momentum transfer. The position of large strain localization in beam 20 due to an increased impact velocity coincides with the point where the stress waves in the reinforcement would collide due to similar velocities of the two propagating waves, which is the mid-point due to symmetry in loading and geometry. A similar phenomenon is shown in e.g. [22], where two stress waves from explosions in a homogeneous media showed large superimposed strain at their collision, which possibly explains the resulting rupture at the mid-point. For beam 19, the strain due to superimposing the stress waves might not have been large enough to cause abrupt rupture, which instead results in wave reflection at the mid-point [21]. The reflective behaviour is similar to that of longitudinal stress waves in finitelength rods hitting a rigid boundary due to symmetry conditions. Each of the two stress waves will due to the reflection travel away from the reflected surface, still as tensile waves due to the boundary condition, and spread the plastic strain evenly along the beam before the mechanical energy of the wave has fully dissipated. This behaviour needs to be researched further.

Figure 14 shows the conclusion drawn from Figure 13: an increased impact velocity results in a large degree of strain localization while a decreased impact velocity results in less localization in the span between the points of momentum transfer. Figure 15 agrees with these conclusions if comparing beams 28 and 29, however, beam 30 shows a lower degree of localization with an increased drop height which deviates from the conclusion. 
Nordic Concrete Research - Publ. No. NCR 65 - ISSUE 2 / 2021 - Article 2, pp. 19-38

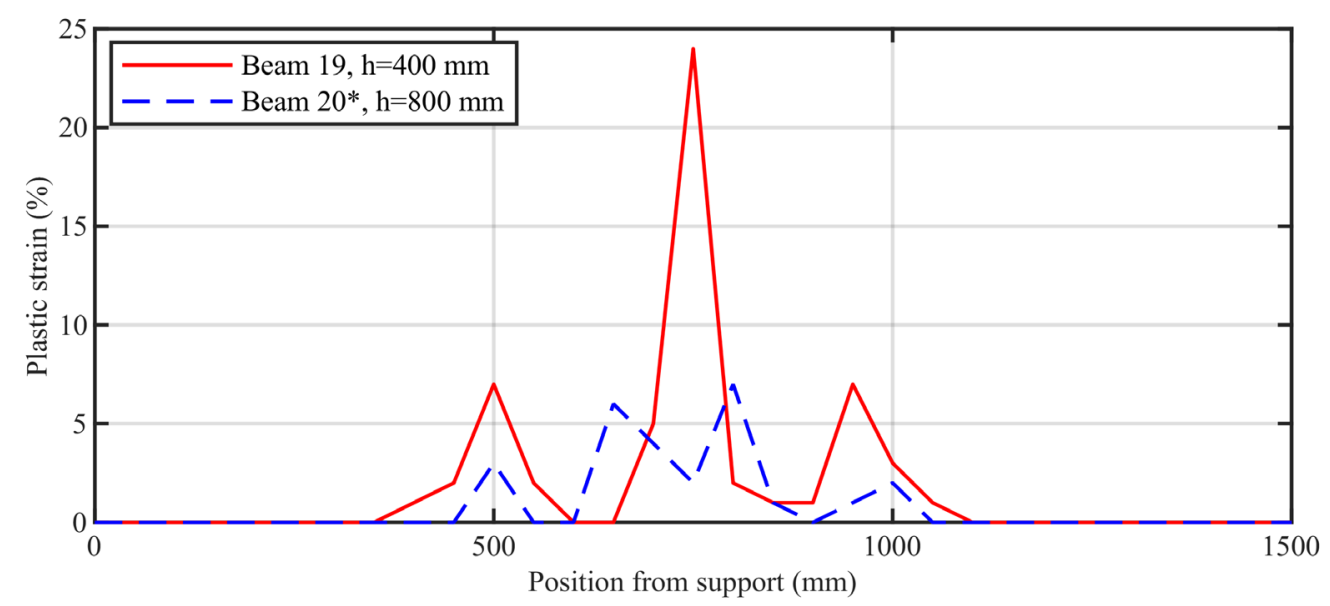

Figure 13 - Plastic strain distribution for beams with a $2 \phi 8$ reinforcement configuration during various drop heights (* indicates rupture of the reinforcement).

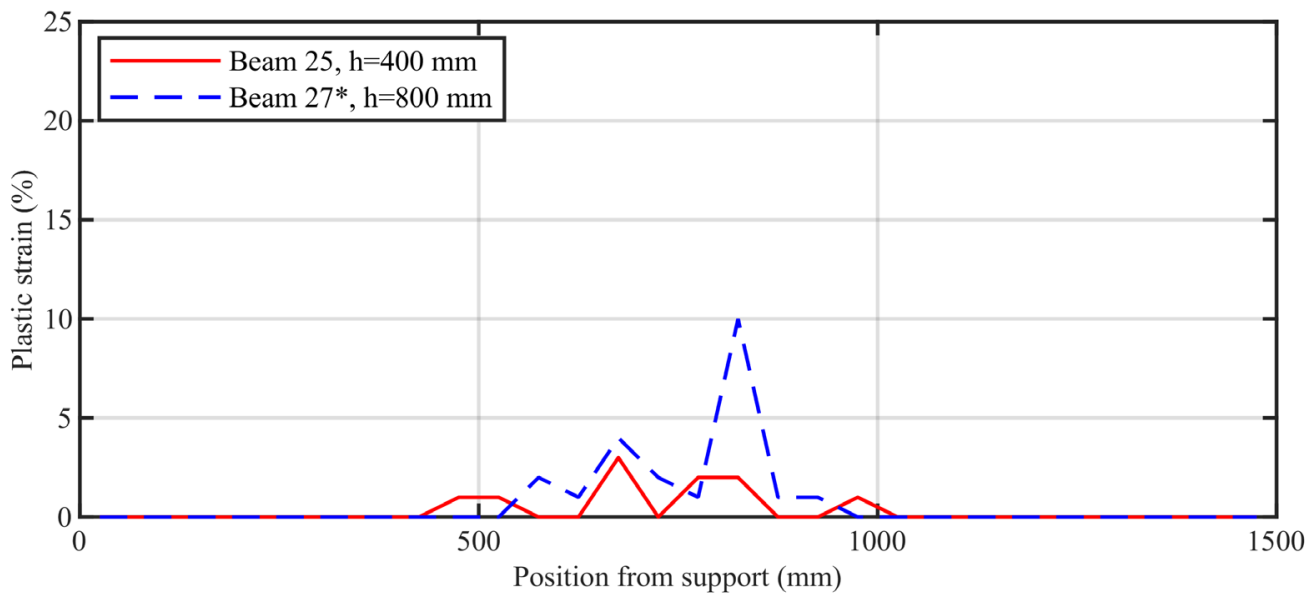

Figure 14 - Plastic strain distribution for beams with a $4 \phi 6$ reinforcement configuration during various drop heights (* indicates rupture of the reinforcement).

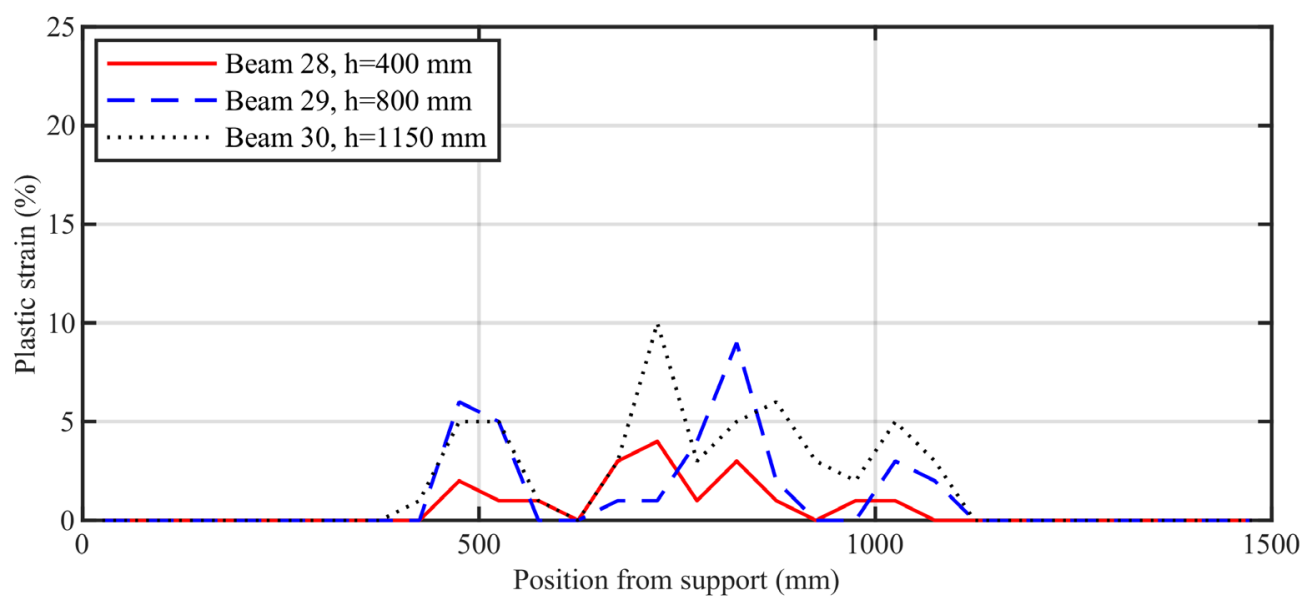

Figure 15 - Plastic strain distribution for beams with a $1 \phi 12$ reinforcement configuration during various drop heights. 
5.

\section{CONCLUSIONS}

The conclusions are here drawn from the discussions and the results that were presented. Each varying parameter is treated separately in a similar manner as before. A negligible effect was shown, on both the plastic strain distribution and the energy absorption capacity of the reinforcement used, even though the compressive strength more than doubled in Section 4.1. The most important implication of this finding is that the concrete quality has little or no influence as a varying parameter for the subsequent comparisons

The effect of the reinforcement strength quality was discussed in Section 4.2. During static loading, the reinforcement quality had a significant impact on the plastic strain distribution, and consequently the energy absorption capacity. Stiff steels with a consolidation region adjacent to the elastic region resulted in a large degree of strain localization towards the centre of the beams. Mild steels instead showed less degree of strain localization. This resulted in a relatively smaller energy absorption capacity of beams using stiff steels when compared to the beams using mild steel. During dynamic loading, the reinforcement quality only showed a significant effect on the strain distribution at low impact velocities. Besides the constitutive behaviour, it was shown that the strain capacity and ultimate strength also played a governing role for the energy absorption capacity. There was, furthermore, indication in Section 4.4 that the reinforcement quality affects the amount of the potential energy of the mass that is absorbed by the reinforcement.

The results presented in Section 4.3 show that static test results coincide with dynamic results for stiff steels; both tests show a large degree of plastic strain localization towards the centre with similar energy absorption capacities. Static and dynamic test results instead disagree for mild steels. Mild steels during static loading show a low degree of strain localization, and the opposite occurs during dynamic tests with large impact velocities.

The comparison of beams with various reinforcement configurations presented in Section 4.4 showed negligible differences in the plastic strain distribution. It was, however, shown that for a similar drop height less energy is stored within the reinforcement as the ratio of the area to the diameter is increased, but the reinforcement qualities used for this comparison were not completely identical. Further research into this is needed. Lastly, there is an indication that an increased diameter with a similar reinforcement area increases the energy absorption capacity.

The impact velocity showed a significant impact on the plastic strain distribution and consequently the energy absorption capacity, as seen in Section 4.5. Increased impact velocities increased the degree of strain localization towards the centre, which became especially apparent when comparing beams containing mild steels.

It was shown that the ductility ratio here did not play an as governing role as hypothesized; all reinforcement types showed a similar ductility ratio (see Table 2) and the energy absorption capacity instead showed to be mainly governed by other material and loading variables.

Numerical analyses will in forthcoming parts of the ongoing larger, overall project on explosions be utilized to investigate these findings further. Especially interesting is wave propagation and inertia effects from varying the impact velocity. The effect from the interaction between the concrete and the reinforcement was partially tested by variation of the reinforcement configuration, but it is deemed that further research is needed. The scope will in later parts of the project expand to also include structures showing flexural shear and direct shear failure modes. 


\section{ACKNOWLEDGEMENTS}

The work in this article is financially supported by the Swedish Transport Administration, the Swedish Fortifications Agency and the Swedish Civil Contingencies Agency (MSB). Their support is gratefully acknowledged. The authors also send their thanks to Göran Svedbjörk at the former Sycon Teknikkonsult AB and Sweco AB.

\section{REFERENCES}

1. Magnusson J: "Shear in Concrete Structural Elements Subjected to Dynamic Loads". PhD Thesis, KTH Royal Institute of Technology, Dept. of Concrete Structures, Stockholm, Sweden, 2019, 160 pp.

2. Chopra A K: "Earthquake Response of Inelastic Systems". Chapter 7, "Dynamics of Structures", Pearson, Harlow, UK, 2017, pp. 243-291.

3. Hanoon A N, Jaafar M S, Hejazi F \& Aziz F N A A: "Energy Absorption Evaluation of Reinforced Concrete Beams under Various Loading Rates Based on Particle Swarm Optimization Technique". Engineering Optimization, No. 49, 2017, pp. 1483-1501.

4. Chen W F: "Elastic Perfectly Plastic Fracture Models". Chapter 6, "Plasticity in Reinforced Concrete Structures”, J. Ross Publishing, Florida, USA, 2007, pp. 253-294.

5. Mosley W H \& Bungey J H: "Design of Reinforced Concrete Beams". Chapter 7, "Reinforced Concrete Design", The Macmillan Press Ltd, London, UK, 1982, pp. 152-192.

6. Fortifikationsförvaltningen: “Instructions for Design of Reinforced Concrete Structures as Protection Against the Action of Conventional Weapons in the Immediate Area". ("Anvisningar för Dimensionering av Armerade Betongkonstruktioner som Skydd mot Verkan av Konventionella Vapen inom Närmissområde”). Stockholm, Sweden, 1973, Publ nr 25:1, 85 pp. (In Swedish).

7. Ansell A \& Svedbjörk G: "Static Testing of Simply Supported Concrete Strips with Reinforcement of Varying Ductility (2000:16)". ("Statisk Provning av Fritt Upplagda Plattstrimlor av Betong med Armering av Varierande Seghet (2000:16)"). Stockholm, Sweden, 2000, 50 pp. (In Swedish).

8. Ansell A \& Svedbjörk G: "Dynamic Testing of Simply Supported Concrete strips with Reinforcement of Varying Ductility (2001:15)". ("Dynamisk Provning av Fritt Upplagda Plattstrimlor av Betong med Armering av Varierande Seghet (2001:15)"). Stockholm, Sweden, 2001, 60 pp. (In Swedish).

9. Ansell A \& Svedbjörk G: "Static and Dynamic Testing of Simply Supported Concrete Strips with Reinforcement of Varying Ductility (2003:8)". ("Statisk och Dynamisk Provning av Fritt Upplagda Plattstrimlor av Betong med Armering av Varierande Seghet (2003:8)"). Stockholm, Sweden, 2003, 63 pp. (In Swedish).

10. Ansell A \& Svedbjörk G: "Static and Dynamic Testing of Concrete Strips Reinforced with Steel of Stiff and Soft Quality". Nordic Concrete Research: Research projects 2002, Helsingör, Sweden, 2002, pp. 45-47.

11. Ansell A \& Svedbjörk G: "Static Testing of Simply Supported Plate Strips with Varying Cross-Sectional Areas (2005: 6)". ("Statisk Provning av Fritt Upplagda Plattstrimlor med Varierande Tvärsnittsareor (2005:6)"). Stockholm, Sweden, 2005, 64 pp. (In Swedish).

12. Ansell A \& Svedbjörk G: "Static Testing of Continuous Concrete Strips with Reinforcement of Varying Ductility (2001:9)". ("Statisk Provning av Kontinuerliga Plattstrimlor av Betong med Armering av Varierande Seghet (2001:9)"). Stockholm, Sweden, 2001, 52 pp. (In Swedish). 
13. Ansell A \& Svedbjörk G: "Dynamic Testing of Continuous Concrete Strips with Reinforcement of Varying Ductility (2002:9)". ("Dynamisk Provning av Kontinuerliga Plattstrimlor av Betong med Armering av Varierande Seghet (2002:9)"). Stockholm, Sweden, 2002, 43 pp. (In Swedish).

14. Ansell A \& Svedbjörk G: "Complementary Dynamic Testing of Continuous Concrete Strips with Reinforcement of Varying Ductility (2003:3)". ("Kompletterande Dynamisk Provning av Kontinuerliga Plattstrimlor av Betong med Armering av Varierande Seghet (2003:3)"). Stockholm, Sweden, 2003, 57 pp. (In Swedish).

15. Peterson V \& Ansell A: "Evaluation of Dynamically Tested Concrete Beams Reinforced with Stiff and Mild Steel Qualities". Proceedings, XXIV Concrete Research Symposium, Sandefjord, Norway, August 2021. (Submitted)

16. Byggstandardiseringen: "Swedish Standard SS 1372 10, Concrete Testing - Hardened Concrete - Cube Strength". ("Svensk Standard SS 1372 10, Betongprovning - Hårdnad Betong - Kubhållfasthet"). Stockholm, Sweden, 2003. (In Swedish).

17. Ihueze C C \& Enetanya A N: "Energy Absorption and Strength Evaluation for Compressed Glass Fibre Reinforced Polyester (GRP) for Automobile Components Design in Crash Prevention Scheme". Journal of Minerals and Materials Characterization and Engineering, No. 1, 2012, pp. 85-105.

18. Johansson M: "Structural Behaviour in Concrete Frame Corners of Civil Defence Shelters”. PhD Thesis, Chalmers University of Technology, Dept. of Structural Engineering, Göteborg, Sweden, 2000, 242 pp.

19. Johansson M \& Laine L: "The Capacity of the Urban Environment Against Extreme Dynamic Action - Part 3: Capacity of Structures". ("Bebyggelsens Motståndsförmåga mot Extrem Dynamisk Belastning - Del 3: Kapacitet hos Byggnader"). Göteborg, Sweden, 2012, 101 pp. (In Swedish).

20. Von Karman T \& Duwez P: "The Propagation of Plastic Deformation in Solids". Journal of Applied Physics, No. 21, 1950, pp. 987-994.

21. Meyers M A: "Elastic Waves". Chapter 2, "Dynamic Behaviour of Materials", John Wiley \& Sons, Inc., New York, USA, 1994, pp. 23-65.

22. Ding C, Yang R \& Feng C: "Stress Wave Superposition Effect and Crack Initiation Mechanism Between Two Adjacent Boreholes". International Journal of Rock Mechanics and Mining Services, No. 138, 2021, pp. 1-9. 


\section{APPENDIX}

When some of the beams in the test series showed identical properties only one was presented for visibility. The beams left out are here presented with the beam used in previous sections to showcase similarities and possible variability. Each subfigure of Figure A use similar material and loading properties.
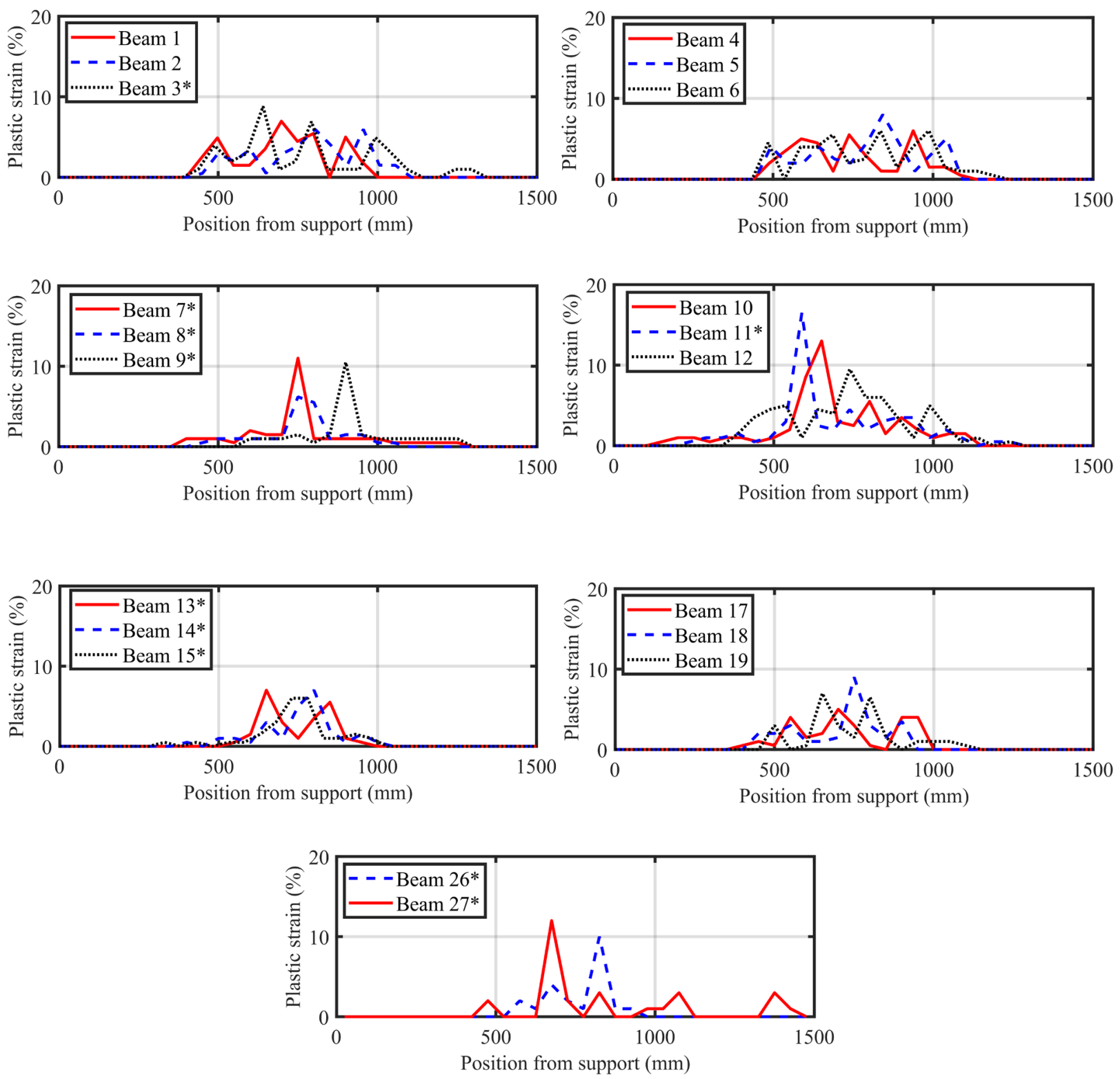

Figure A-Plastic strain distribution for beams with similar properties $(*$ indicates rupture of the reinforcement). 